\title{
Enfermedades respiratorias ocupacionales
}

\section{Occupational respiratory diseases}

Muchas personas tienen la oportunidad de ingresar al campo laboral para desarrollar aquello que los lleva a alcanzar la realización personal en uno de los aspectos importantes de la vida. La mayoría, sin embargo, sólo aspira a obtener ingresos que le permitan subsistir. Unos y otros comparten la esperanza de terminar su vida laboral en buenas condiciones de salud fisica y económica, que les permita disfrutar la etapa final de la vida.

Pero desde que el hombre empezó a trabajar, descubrió que esa actividad tenía riesgos asociados y que ellos podían generar una o varias enfermedades. Luego de miles de años, la situación no ha cambiado. Prácticamente no existen actividades productivas en las que no exista el riesgo de enfermar por causa del trabajo.

En nuestro país contamos con dos sistemas paralelos de protección de la salud de los ciudadanos; uno es el destinado a enfrentar los apremios causados por enfermedades de origen no laboral ("enfermedades comunes" en la jerga de quienes se dedican a la salud ocupacional) y otro destinado a proteger la salud de los trabajadores.

El $1^{\circ}$ de febrero de 1968 se publicó la Ley 16.744 que "Establece Normas sobre Accidentes del Trabajo y Enfermedades Profesionales" y que rige el sistema de protección de la salud de los trabajadores hasta hoyl. La condición de trabajador cubierto por esta Ley está definida como "toda persona, empleado u obrero que trabaje para alguna empresa, institución, servicio o persona". La relación entre empleado y empleador la define un contrato de trabajo, sea éste escrito o verbal. La condición de enfermedad profesional queda definida como aquella "causada de una manera directa por el ejercicio de la profesión o el trabajo que realice una persona y que le produzca incapacidad o muerte".

En nuestra condición de Especialistas en Enfermedades Respiratorias la relación con la Ley 16.744 se produce en tres maneras. Por una parte, en nuestra condición de "trabajadores", estamos expuestos a riesgos que nos pueden generar una enfermedad profesional, la que tendrá la cobertura señalada en la Ley. Por otra, en nuestra condición de "especialistas", nos corresponde diagnosticar, tratar y evaluar el grado de incapacidad que producen a los afectados, las enfermedades respiratorias profesionales. Por último, aquellos de nosotros que se convierten en "empleadores", deben cuidar que la salud de sus colaboradores no se deteriore producto de la actividad productiva. Todos estos aspectos serán considerados en detalle en una próxima publicación.

Con no poca frecuencia se nos pide señalar cuál es la importancia de las enfermedades respiratorias profesionales dado que para muchos es un tema desconocido. Para responder la pregunta debemos recurrir a nuestra experiencia o a lo publicado en la literatura internacional, porque las publicaciones cientificas nacionales son escasas y las estadísticas sobre la frecuencia de estas patologías en nuestro país son inexistentes. Por ejemplo, la experiencia nacional indica que la silicosis es la enfermedad respiratoria más importante, pero la literatura internacional señala que la más relevante es el asma ocupacional $^{2}$.

Respecto de la silicosis, un estudio realizado por el Instituto de Salud Pública de Chile y publicado en 2008, estimó que el 5,4\% de los trabajadores (más de 340.000 personas) están expuestos a sílice 3 . Los rubros que más riesgo generan son la Minería (más que nada las pequeñas y medianas empresas), la Agricultura y la Construcción, sin embargo, cualquier actividad en la que se fracture roca o se trabaje con roca fracturada, puede generar silicosis en los trabajadores. El número real de expuestos está, muy probablemente, subestimado.

La importancia de la silicosis a nivel global ha llevado a la Organización Mundial de la Salud (OMS) y a la Organización Internacional del Trabajo (OIT) a proponer un plan para erradicar esta enfermedad del planeta, teniendo como base el concepto de que el ser humano no está capacitado para 
respirar cuarzo y que la exposición es totalmente evitable. Chile es uno de los países que forma parte de esta iniciativa y el trabajo que se ha desarrollado en esa línea ha sido liderado por los especialistas en Salud Ocupacional'. La contribución de nuestra sociedad de especialistas a este noble objetivo está pendiente.

Respecto del asma ocupacional, se debe también señalar que su frecuencia es desconocida. Se estima que entre el 9 y 15\% de los casos de asma de inicio en adultos son de origen ocupacional; sin embargo, esta cifra debe también estar subestimada. A la fecha son más de 400 los agentes causantes de asma ocupacional reconocidos en la literatura internacional. Sin embargo, cualquier proteína o molécula inhalada es potencialmente capaz de generar una reacción inflamatoria de las vías aéreas, sea esta del tipo alérgico o no alérgico.

El asma ocupacional ${ }^{2}$ tiene una característica que no tienen los otros tipos de asma ni tampoco tiene la silicosis; si el paciente es retirado a tiempo de la exposición, puede mejorar al grado de no requerir tratamiento mientras no se exponga nuevamente a aquello que le causó la enfermedad. El retiro de la exposición es una herramienta terapéutica que debería estar al principio de la lista de tratamientos que nosotros, especialistas en enfermedades respiratorias, podemos ofrecer a nuestros pacientes.

En la medida que el hombre crea nuevas actividades productivas, el número de agentes causantes de asma ocupacional sigue creciendo y con ello la población trabajadora en riesgo. Los agentes más frecuentemente asociados a esta enfermedad son los isocianatos, harina y polvos de granos, colofón, látex, aldehídos y aserrín de maderas. Los trabajadores más comúnmente afectados son los pintores o barnizadores, panificadores y pasteleros, enfermeras, trabajadores de la industria química, manipuladores de animales, soldadores, trabajadores de la industria de alimentos y de la madera.

Las Enfermedades Respiratorias Ocupacionales cubren un amplio espectro de patologías, desde las inflamatorias (alérgicas y no alérgicas) las irritativas, las infecciosas, los cánceres, las generadas por factores ambientales como la hipoxia hipobárica de la altitud, las alteraciones del sueño producto de trabajo en ambientes extremos o en sistemas de turno, entre otras. Es por ello que creemos que las Enfermedades Respiratorias Ocupacionales deben constituir un tema relevante en nuestra sociedad de especialistas, y es por ello que celebramos que nuestra propuesta de crear un grupo de trabajo en temas de salud ocupacional haya sido aceptada y que la invitación a participar que se ha hecho a varios especialistas haya sido respondida con entusiasmo. El cuadragésimo sexto congreso de nuestra especialidad vio surgir esta iniciativa asociada a la Comisión de Tabaquismo y Contaminación Ambiental.

Las tareas que como grupo enfrentamos son muchas y nos será difícil establecer a cual dar prioridad, pero sin duda que entre ellas estará la capacitación, difusión e investigación. Las dos primeras ayudarán a que las enfermedades respiratorias profesionales sean reconocidas y estimada su importancia real. La investigación nos permitirá cumplir con uno de nuestros roles como especialistas, que es el de aportar al conocimiento en esta importante área de nuestro quehacer.

Dr. Gustavo Contreras T., Coordinador

Dra. Bernardita Torrealba J., Coordinadora alterna

Subcomisión de Salud Ocupacional,

Comisión de Tabaquismo, Contaminación Ambiental y Salud Ocupacional, Sociedad Chilena de Enfermedades Respiratorias

\section{Bibliografía}

1.- Ley 16.744. Establece Normas sobre Accidentes del Trabajo y Enfermedades Profesionales. Gobierno de Chile. Publicada $1^{\circ}$ de febrero de 1968.

2.- NICHOLSON P J, CULLINAN P, BURGE P S, BOYLE C. Occupational asthma: Prevention, identification \& management: Systematic review \& recommenda- tions. British Occupational Health Research Foundation. London. 2010.

3.- ALCAÍNO J, SOLIS R, QUINTANILLA P. Estudio de Exposición de la Sílice. Chile 2004-2005. Instituto de Salud Pública de Chile. 2008.

4.- BERNALES B, MARCHETTI N, JARAMILLO H. Plan Nacional para la Erradicación de la Silicosis. Gobierno de Chile. 2008. 